\begin{tabular}{|c|l|}
\hline Title & A Itruism toward in-group members as a reputation mechanism \\
\hline Author(s) & Mifune, Nobuhiro; Hashimoto, Hirofumi; Y amagishi, Toshio \\
\hline Citation & $\begin{array}{l}\text { Evolution and Human Behavior, 31(2), 109-117 } \\
\text { https://doi.org/10.1016/.evol humbehav.2009.09.004 }\end{array}$ \\
\hline Issue Date & 2010-03 \\
\hline Doc URL & http://hdl.handle.net/2115/43078 \\
\hline Type & article (author version) \\
\hline File Information & EHB31-2_109-117.pdf \\
\hline
\end{tabular}

Instructions for use 


\title{
Altruism toward In-group Members as a Reputation Mechanism
}

\author{
Nobuhiro Mifune \\ Hirofumi Hashimoto \\ Toshio Yamagishi
}

Hokkaido University, Japan

September, 2009

The studies reported in this paper was supported by Grant-in-aid 19330139 by Japan Society for the Promotion of Science to the last author. We would like to thank colleagues at Hokkaido University who generously let us recruit potential participants from their classes. We also thank Victoria Yeung and Joanna Schug for helping us improving the manuscript. 


\begin{abstract}
To test the hypothesis that sensitivity to monitoring drives people to act altruistically toward members of their own community, two experiments investigated whether an eye-like painting promotes altruism toward in-group members, but not toward out-group members. Participants played the role of dictator in a dictator game with another participant (a recipient) who was from the minimal in-group or out-group. Participants knew if their recipient was an in-group member or an out-group member, but were informed that their recipient did not know the group membership of the proposer. In-group favoritism occurred only when participants were facing a computer desktop which displayed a painting of eyes, but did not occur in the absence of eyes. These findings demonstrate that the eye painting displayed on the participant's computer screen worked as a cue for monitoring, and thus enhanced the participant's altruistic behavior.
\end{abstract}

(Total: 140 words) 


\section{INTRODUCTION}

Altruism toward genetically unrelated individuals whom one is not likely to meet again is an evolutionary puzzle. This is because the standard explanations of altruism among animal species, including kin selection (Hamilton, 1964) and reciprocal altruism (Trivers, 1971), are incapable of explaining altruism toward genetically unrelated individuals whom one is not likely to interact with again. From an evolutionary perspective, such altruistic behavior seems to be, at least on the surface, only detrimental to one's inclusive fitness. And yet, such behavior is not unusual; many people anonymously donate money to various charities, and participants in both laboratory and field experiments who are strangers to each other, behave in altruistic and cooperative manners even in one-shot encounters (Berg, Dickhaut, \& McCabe, 1995; Fehr \& Fischbacher, 2003; Forsythe, Horowitz, Savin, \& Sefton, 1994; Gintis, Bowles, Boyd, \& Fehr, 2003; Henrich et al, 2006; Hoffman, McCabe, \& Smith, 1996; Ledyard, 1995; Messick \& McClintock, 1968). In this study, we present experimental evidence in support of the proposal that such altruism can be understood as an implicit strategy to adapt to a system of indirect reciprocity.

The growing literature on indirect reciprocity in theoretical biology aims to provide an answer to this evolutionary puzzle. Altruistic behavior toward someone whom one never sees again will not be rewarded by the recipient of such behavior. This effectively eliminates the possibility for altruists to acquire gains through mutually altruistic behavior, that is, what Trivers (1971) calls reciprocal altruism. This, however, does not eliminate the possibility that altruists are indirectly reciprocated by other altruists. When other altruists are conditional altruists, or those who behave altruistically only toward other altruists but not toward egoists, it is possible for altruists to acquire 
more benefits than egoists. Thus, altruism can evolve when there is a sufficiently large number of conditional altruists in a community, such that the extra benefits an altruist receives from conditional altruists exceeds the cost of behaving altruistically toward others.

It should be noted, however, that conditional altruism can evolve only under specific conditions. Several models have been proposed as candidates for specifying the exact nature of these conditions (e.g., Nowak \& Sigmund, 1998; Leimar \& Hammerstein, 2001; Panchanathan \& Boyd, 2004; Takahashi \& Mashima, 2006). In this paper, we do not discuss the similarities and differences among those models. Instead, we would like to point out that, despite some differences in the specification of the conditions for being a recipient of conditional altruism, information about one's past behavior toward others plays a crucial role in the success of all indirect reciprocity models. Unless one's altruistic or egoistic behavior toward others is known to the other conditional altruists, conditional altruism cannot function. In other words, reputation about one's behavior plays an indispensable role for the success of conditional altruism as a fitness-enhancing strategy.

In all of the models of indirect reciprocity cited above, transparency of information about all community members' past behavior is assumed, though the models differ from each other in the nature of the information available to other members. For example, the "image scoring” model proposed by Nowak and Sigmund (1998) requires the availability of information about others' immediate past - i.e., whether each of the other members of the community acted altruistically or not in the immediately preceding trial. The other models, such as the "standing” model proposed by Leimar and Hammerstein (2001), the "extra standing” model and the "strict 
discriminator" model proposed by Takahashi and Mashima (2006), require further information; the players in these models are assumed to know, for example, if someone behaved altruistically toward someone else in the previous trial, and, further, if that someone else behaved altruistically toward yet another person two trials ago. Despite these differences, a fundamental assumption shared by all of these models is that all players' immediate past behavior is known to all of the other players. In this study, we seek to examine the psychological implications of this fundamental assumption used in various models of indirect reciprocity.

One immediate psychological implication of the above assumption is that humans are sensitive to how others behave toward members of their own community. In their cheater detection studies, Cosmides and Tooby (1989) have demonstrated that humans are sensitive to others' behavior, especially if others' behavior does not meet the moral standard of the community. Wang (1996) further demonstrated that such sensitivity to other members' behavior is stronger in smaller groups than in larger groups.

What we want to pursue in this study is another psychological implication of the above assumption, which is as obvious as the first one, but has not been fully explored yet. That is, humans are sensitive to the fact that their behavior is being observed by other community members. People must behave in a way to enhance their reputation of behaving altruistically toward their community members in order to qualify as someone who deserves similar treatment from other members of the community. The fact that people generally behave in a more cooperative and altruistic manner when their behavior is observed as opposed to when under complete anonymity has been repeatedly demonstrated in experimental studies. For example, face-to-face 
contact between game players (a situation where players can observe each other's behavior) has been repeatedly demonstrated to enhance cooperation level in prisoner's dilemma and other related games (e.g., Bixenstine, Levitt, \& Wilson, 1966; Brechner, 1977; Dawes, McTavish \& Shaklee, 1977; Kurzban, 2001). In other studies, participants were found to behave in a more altruistic manner when they expected that their reputation would spread to other participants (Barclay, 2004; Barclay \& Willer, 2007; Milinski, Semmann, \& Krambeck, 2002).

Accumulating evidence suggests that people are sensitive not only to the explicit information that their future rewards depend on how others perceive and judge their behavior, but also to subtle cues suggesting that they may be monitored by others. A good example is found in a study by Bateson, Nettle and Roberts (2006), which demonstrated that users of a common coffee machine in an office voluntarily donated more money to maintain the supply of coffee when a poster of eyes was posted on the wall than when a poster of flowers was posted. The presence of the eyes is assumed to function as a cue to the presence of monitoring in this situation, thus enhancing the altruistic behavior. Burnham (2003) demonstrated that presenting a picture of the recipient to the dictator in a dictator game prompted the dictator to allocate more money to the recipient. In another experiment of a dictator game, Haley and Fessler (2005) found that participants who played the role of a dictator voluntarily gave more share of an endowment of $\$ 10$ when their computer screen displayed a painting of eyes. Burnham and Hare (2007) added further evidence to the effect of eyes on a computer screen by presenting a robot figure which appeared to be looking forward. They found that the presence of the robot on the computer screen promoted the cooperation level in a public goods game. Findings in these studies suggest that the presence of eye figures 
functions as a cue to the operation of monitoring in the situation, prompting participants to act in a more altruistic manner. Furthermore, Rigdon, Ishii, Watabe and Kitayama (2008) found that even an abstract figure remotely resembling a human face can have the same effect in a dictator game experiment in which participants were presented with three black dots in either the shape of a triangle, “.”, or an upside-down triangle. In their study, participants allocated more money to the recipient when they saw an upside-down triangle of three dots, which remotely resembles human face, than when they saw a straight triangle. These findings provide support to the view that at least some of pro-social behavior frequently observed in one-shot games is a product of intuitive decision making driven by subtle but salient cues. Such a cue-driven psychological mechanism operates independently of the process of explicit decision making in which relevant pieces of information are deliberately evaluated and compared.

As shown above, we already have substantial evidence that humans are sensitive to cues suggesting the presence of monitoring and respond to such cues in the form of enhanced altruistic behavior. The goal of the current study is to add a new piece of evidence showing that such sensitivity to reputation operates mostly within one's own group where one's reputation matters most. Such sensitivity to monitoring by others should be heightened when those observing one are members of one's own community, rather than strangers. This is because the information about one's behavior held by a stranger is not very likely to be transmitted to someone with whom one may later interact. In contrast, if the same piece of information is held by a member of one's own community it is more likely to be transmitted to other community members with whom one is likely to interact with. 
In explaining in-group favoring reward allocation in a dictator game, Yamagishi and Mifune (2008) argued that altruistic behavior is fitness enhancing when it is directed toward, and is observed by, community members, as only the community members are in a position to repay altruistic acts through indirect reciprocity. In other words, behaving altruistically toward outsiders to their own community or being observed by outsiders does not qualify the altruist as a recipient of altruistic behavior by other community members. In order to test this argument, they compared two conditions concerning the commonality of group membership information. In their study, participants were first divided into one of two minimal groups (Tajfel, Billig, Bundy, \& Flament, 1971), and played a dictator game as a dictator. Minimal groups are artificially created in the laboratory by categorizing participants into one of several groups based on a trivial criterion such as preference for painters. No communication or interaction within and across groups is allowed. In one condition, the recipient of the money the dictator allocated was an in-group member. In the other condition, the recipient was an out-group member. These two conditions were crossed by another experimental manipulation concerning the knowledge the two players had about their group membership. In the "common knowledge” condition, both the participant (dictator) and the recipient mutually knew which group they both belonged to. In the private knowledge condition, only the participant knew which group they both belonged to, and the recipient did not know which group the dictator (i.e., the participant) belonged to. Yamagishi and Mifune predicted that participants would allocate more money to an in-group recipient than to an out-group recipient only in the common knowledge condition. According to the logic presented earlier, being identified as a community member by other community members is a necessary condition for the reputational 
function of acting altruistically to operate. This was the exact situation in which Yamagishi and Mifune's participants faced in the common knowledge condition. This explains why participants behaved more altruistically toward in-group members than out-group members. On the other hand, since participants in the private knowledge condition were not identified by their own group member, making the situation irrelevant to reputation concerns, no altruism enhancement toward in-group members was found in this condition. Similar results have been repeatedly demonstrated in simultaneously played prisoner’s dilemma games (Jin \& Yamagishi, 1997; Kiyonari, 2002; Yamagishi, Jin, \& Kiyonari, 1999; Yamagishi, Makimura, Foddy, Matsuda, Kiyonari, \& Platow, 2005; Yamagishi, Mifune, Liu, \& Pauling, 2008), a sequentially played prisoner's dilemma game (Horita \& Yamagishi, 2007), and some variations of the trust game (Foddy, Platow \& Yamagishi, 2009; Kiyonari, Foddy, \& Yamagishi, 2007; Suzuki, Konno, \& Yamagishi, 2007).

The purpose of this study is to provide further evidence to support Yamagishi and colleagues' argument that in-group favoring behavior that was observed in the minimal group settings can be best explained as an adaptive response to the indirect reciprocity environment. In this paper, we used the private knowledge condition that has been reported to produce no in-group favoring effect as a control, and manipulated cues of monitoring (presence versus absence of stylized eyes image). We seek to demonstrate that displaying the stylized eyes on the participant's computer screen would have a similar altruism-enhancing effect to commonality of knowledge in Yamagishi and Mifune's (2008) study.

If in-group favoring behavior in the minimal group setting is driven by a psychological mechanism that makes people adapt to indirect reciprocity environments, 
participant's sensitivity to monitoring should be stronger when they deal with community members (in-group) than when they dela with someone who is known to be a stranger (out-group). According to this logic, we expect that even in the private knowledge condition, the altruism-enhancing effect of eye figures demonstrated by Haley and Fessler (2005) should be more likely to occur when participants play a dictator game with an in-group recipient than when they play the game with an out-group recipient.

\section{STUDY 1}

Two experiments were conducted. The goal of the first experiment was to demonstrate that in-group favoring behavior occurs even in the private knowledge condition when participants face a salient cue of monitoring. Both experiments used only the private knowledge condition in which the previous study (Yamagishi \& Mifune, 2008) found no in-group favoring behavior; the common knowledge condition was not used in either of the two experiments. We did not include in the first study the condition in which the salient cue of monitoring-i.e., the stylized eyes-was not present, because Yamagishi and Mifune (2008) have established that in-group favoring behavior is absent in the private knowledge condition in the absense of eyes.

\section{Method}

Participants. Participants were eighty-four (31 females and 53 males) freshmen at Hokkaido University, Japan, who were recruited from a large participant pool consisting of students from various departments on campus. Monetary rewards were emphasized as incentives for their participation.

Dictator Game. Participants were randomly assigned to the role of either a dictator (called bunpaisha or "allocator" in the study) or a recipient (called ukete). Each 
allocator was endowed with 900 yen (about \$8) from the experimenter and was asked to divide it between the two players in one of the following three ways: a) 800 yen for him/herself and 100 yen for the recipient, b) 600 yen for him/herself and 300 yen for the recipient, or c) 450 yen for each player. The group membership of the recipient was manipulated as a between-participants factor, such that allocators made the allocation decision only once, between themselves and either an in-group recipient or an out-group recipient.

Procedure. After receiving an ID number from a receptionist, each participant was escorted to a private cubicle where he/she stayed till the experiment was over. The anonymity of participants' behavior was completely secured through the use of the ID numbers throughout the experiment. All participants sat in front of a computer which displayed a drawing of eyes resembling the makeup of a traditional Japanese kabuki actor (see Figure 1). This picture was adopted from a poster used by Tokyo Metropolitan Government on crime prevention, with the permission of the responsible section of the government. The picture was displayed on the screen until the start of the “picture preference test” (which we will describe in the following).

Participants were asked to do two tasks during the experiment — a "picture preference test” and a dictator game. They first took the picture preference test, during which the drawing of eyes was not present on the computer desktop. In this task, 28 pairs of paintings (one painted by Paul Klee and the other by Wassily Kandinsky) were displayed on participants' computer screen, and they were asked to indicate, for each pair, which painting they liked more. Based on the relative preferences of the participants among those who participated in the same session, they were divided into two groups, either a Klee group or a Kandinsky group. Immediately after they were 


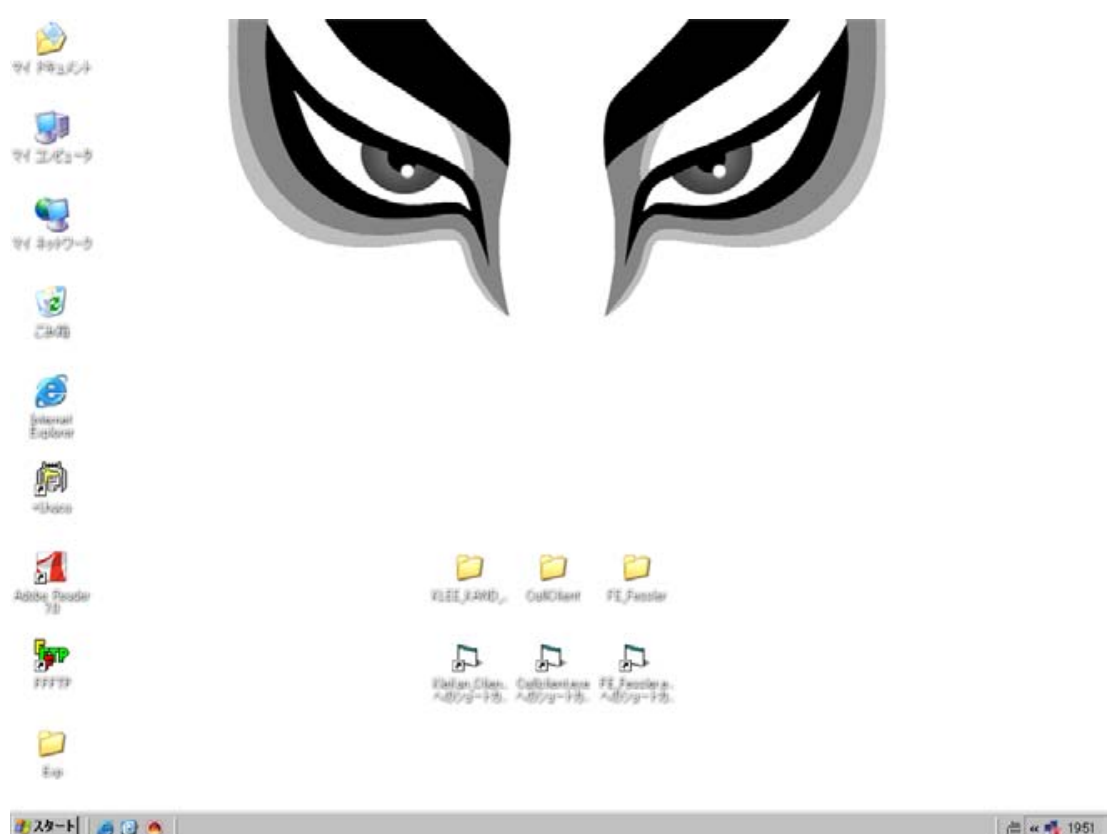

Figure 1. Kabuki eyes used in the first and the second experiments

divided into the two minimal groups, identity scales based on Grieve and Hogg (1999) were administered to measure their levels of identification with the in-group and the out-group. When the participant completed the identity scale, the program on the computer closed and the original desktop with the drawing of eyes appeared. The picture preference task took about 10 minutes including the division of participants into the two minimal groups and the administration of identity scales. Participants were paid 500 yen for this task.

Before starting the second task, the experimenter came into the participants' cubicle and started another computer program which activated a "call button" on the computer screen. The call button appeared right below the eyes figure on the screen. Participants were instructed to click the button whenever they wanted to or were asked to call the experimenter. This procedure was designed to strengthen the manipulation in 
such a way that every time participants used the call button, they saw the eyes located above.

The dictator game was conducted in the same cubicles using the paper and pencil method. However, the computer kept displaying the call button and the desktop with the eye figures. The experimenter delivered the instructions to each participant, and, in addition, asked them to choose one envelope from a set of six envelopes. The instructions explained the nature of the dictator game, including the assignment of the participants into one of the two roles - allocator or recipient. Participants were told that the aim of the experiment was to learn about allocation behavior, and for this purpose, participants were assigned to the role of allocator or recipient. The allocator would receive 900 yen from the experimenter, and decide how to divide the money between him/herself and a recipient. The allocator's decision would be completely anonymous to the experimenter who did not know which condition participants were in. Furthermore, all responses from the participants were collected in envelopes, and were delivered to another experimenter, who never met the participants or knew their names. The second experimenter recorded allocators' decisions and put money into the recipients' envelopes.

At the end of the game instructions, participants were asked to open the envelope they had chosen earlier and remove the second set of instructions. The second instructions told the participant which role he/she was assigned to. In addition, participants who had unwittingly chosen the allocator's role were given further instructions concerning the actual procedure of determining how to divide the money. The procedure by which the anonymity of their choices would be protected was also clearly spelled out. Participants were asked to call the experimenter by clicking on the 
call button when they finished reading the second instructions. The experimenter then came in with another set of envelopes, and asked the participant to choose one. After the experimenter left the cubicle, the participant opened the second envelope and took out the assignment sheet that indicated whether the matched partner was an in-group member or an out-group member. The dictator game started once all participants finished reading this last piece of information. Participants then made their allocation decision. They were told that the decision sheet would be delivered to the matched recipient. The recipient simply received the amount of money the allocator decided to give him/her.

The private nature of the group membership knowledge was explicitly provided to the participants in the following two ways. First, they were told in the instructions that their partner would not be given information concerning which of the two groups the participant belonged to. Specifically, the participant who had been assigned to the role of allocator was instructed that their partner (recipient) would not know which group member he/she received money from. In addition to these instructions, two adhesive labels were affixed to the allocator's decision sheet and the envelope for the decision sheet. The participant's group membership was printed on one label, and their partner's group membership was printed on the other. The participants were asked to remove the label indicating their group membership from both the decision sheet and the envelope. This procedure reinforced the private nature of the group membership since it made clear that their partner who received the decision sheet in the envelope would never see the group membership of the participant.

After the dictator game was over, a post-experimental questionnaire was administered to measure if participants correctly understood the instructions. 
Participants were then paid the amount the allocator decided, plus the 500 yen for the completion of the picture preference task. The experiment took about an hour.

\section{Results}

Since Recipients did nothing during the experiment, the following analyses were conducted only with data from Allocators who actively and solely made decisions.

In-group identity. In order to make sure that participants identified with their minimal group, we analyzed their identity scores toward the in-group and the out-group following Grieve and Hogg (1999). The identity score with the in-group ( $M=4.46$, $s d=$ 1.43, on a 9-point scale) was found to be significantly greater than that with the out-group $(M=4.25, s d=1.18 ; t(83)=1.75, p=.04$, one-tailed, $d=.16)$. The minimal group manipulation was successful in producing a stronger identity with the in-group than the out-group.

Allocator's choice behavior. The frequency of each choice is shown in Table 1. While the frequencies of the three choices toward the in-group recipient did not significantly differ from those toward the out-group recipient $\left(\chi^{2}(2)=2.73, p=.26\right)$, the proportions of equal divisions (i.e., choice option c) significantly differed between the two recipient conditions $\left(\chi^{2}(1)=3.88, p=.05\right)$. That is, when the recipient was an in-group member, participants chose the equal division of the endowed money (64.3\%) more frequently than when the recipient was an out-group member (42.9\%). In other words, our participants showed a tendency to behave in a more altruistic manner toward an in-group member than an out-group member even in the situation which previous studies had found no such effect in the absence of salient cues of monitoring. 
Table 1 Frequencies of Allocator's choice in the first experiment

\begin{tabular}{cccc}
\hline Recipient & $\begin{array}{c}\mathrm{A} \\
(800 / 100 \text { yen })\end{array}$ & $\begin{array}{c}\text { B } \\
(600 / 300 \text { yen })\end{array}$ & $\begin{array}{c}\text { C } \\
(450 / 450 \text { yen })\end{array}$ \\
\hline In-group & $\mathbf{1 0}(23.8 \%)$ & $\mathbf{5}(11.9 \%)$ & $\mathbf{2 7}(64.3 \%)$ \\
\hline Out-group & $\mathbf{1 4}(33.3 \%)$ & $\mathbf{1 0}(23.8 \%)$ & $\mathbf{1 8}(42.9 \%)$ \\
\hline
\end{tabular}

The purpose of the first experiment was to demonstrate that, although Yamagishi and Mifune (2008) had shown that the private knowledge condition eliminates in-group favoritism in a minimal group paradigm, the effects of the absence of common knowledge can apparently be ameliorated by the presence of eyes, a cue that one is being observed. With the success of this first experiment, we moved on to demonstrate that it is actually the presence/absence of the eyes figure that made the participants behave more altruistically toward in-group members than toward out-group members. In order to clearly demonstrate the role of "eyes" in promoting altruistic behavior toward community members, systematical manipulation of the presence and absence of the eyes figure via the random assignment of the participants is needed. We thus conducted a second experiment in which participants were randomly assigned to one of the two between-participants conditions-presence and absence of eyes figure.

\section{STUDY 2}

The design of the second experiment was the same as that of the first experiment, except for the following three aspects. First, we added a second condition of no eyes present. Second, whereas the allocators's choice was limited to three options in the first study, in the second study, the allocator was allowed to divide the money any 
way they preferred (in increments of 10 yen). Third, instead of using only kabuki eyes as in the first study, we also used the Horus eyes figure adopted from Haley and Fessler (2005).

\section{Method}

Participants. One hundred and forty-two (66 females and 76 males) undergraduate students at Hokkaido University, Japan, were recruited from the same participant pool as the one used in the first study, though none of the participants in the first study participated in the second study. Monetary rewards were emphasized as incentives for participation.

Design and procedure. A 2 (recipient's group: in-group and out-group) x 3 (eye condition: no eyes, kabuki eyes, and Horus eyes) between-participant design was used. Since we planned to pool the two eye conditions unless we found significant differences there, we assigned a larger number of participants to the control (no eyes) condition $(\mathrm{n}=62)$ than to the kabuki eyes condition $(\mathrm{n}=39)$ or the Horus eyes condition ( $\mathrm{n}=41)$. We used a picture of a green field (Windows' wall paper "bliss”) as the desktop for the control condition. The procedure used in the first study was repeated.

\section{Results}

As in the first study, only the allocator's data were used for analysis. We discarded results from two participants who indicated in the post-experimental questionnaire that they thought that both themselves and their partner would receive a predetermined amount of money from the experimenter regardless of their decision.

In-group identity. Participants' mean identity score with the in-group was 4.51 ( $s d=1.36$ ), and was significantly greater than the mean identity score with the out-group $(M=4.21$, sd $=1.13 ; t(139)=2.83, p=.005, d=.24)$. This result 
demonstrates that the minimal group manipulation succeeded in producing differential identity with the two groups.

Allocator's choice behavior. We first conducted a preliminary analysis to see if the two types of eyes (kabuki and Horus) had differential altruism-enhancing effect, and found that the eye type did not significantly interact with the recipient group $(F(1,74)$ $=0.06, p=.80$ ) in a recipient group $\mathrm{x}$ eye type analysis of variance. Therefore, we combined the two eyes conditions together and compared the combined eyes condition (including both kabuki and Horus eyes types) with the no-eyes, control condition.

Figure 2 shows the distribution of allocated money to the in-group recipients and the out-group recipients in the eyes and no eyes conditions, respectively. Since the frequency distribution of the amount allocated to the recipient was highly skewed and bimodal, we decided to supplement the analysis of variance results with the log-linear analysis of binary dependent variable of fair (450 yen or more to the recipient) and unfair (less than 450 yen to the recipient) allocations. 


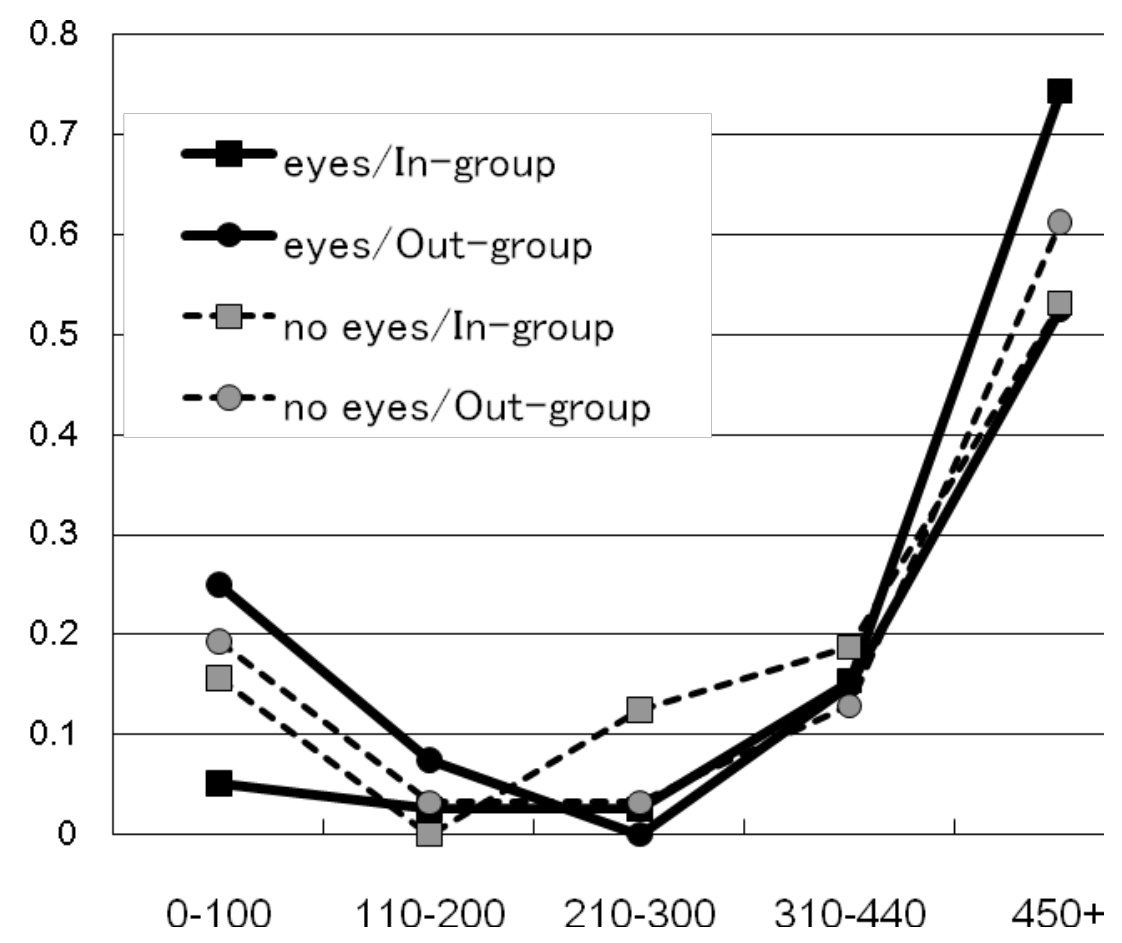

Figure 2 Distributions of the amounts allocated to the in-group and the out-group recipients in the eyes and the no-eyes conditions (in relative proportions) in the second experiment

The predicted interaction effect of the presence/absence of eyes and the recipient's group (in-group vs. out-group) was significant $\left(F(1,136)=4.27, p=.04 ; \chi^{2}\right.$ $(1)=4.20, p=.04)$. The main effects of the eyes $\left(F(1,136)=0.01, p=.92 ; \chi^{2}(1)=\right.$ $1.09, p=.30)$ and the recipient's group $\left(F(1,136)=1.37, p=.24 ; \chi^{2}(1)=0.89, p\right.$ $=.35$ ) were not significant. Figure 3 displays the average amounts of money and the proportions of the fair allocation that the allocator gave to the in-group and the out-group recipients in the eyes condition and the no-eyes condition. The significant interaction effect indicates the presence of the in-group favoring behavior in the eyes condition $\left(F(1,136)=5.91, p=.02 ; \chi^{2}(1)=4.66, p=.03\right)$ and its absence in the no-eyes condition $\left(F(1,136)=0.36, p=.55 ; \chi^{2}(1)=0.59, p=.44\right)$. While the figure seems to suggest a slight out-group favoring pattern, the difference between the 
amounts allocated to the out-group and the in-group recipients was far from being significant. The absence of the in-group favoring behavior in the standard private knowledge condition thus successfully replicated the previous findings by Yamagishi and Mifune (2008). In contrast to this, the in-group favoring pattern observed in the eyes condition successfully replicated the same pattern found in the first study.

The same interaction effect seen from another perspective indicates that the presence of eyes caused allocators to give more of the endowment to the recipient when the recipient was a member of the allocator's own group. While the simple main effect of the eyes in this condition did not reach the significance level in the analysis of variance $(F(1,136)=2.33, p=.13)$, the same effect was significant in the log-linear analysis of fair allocation $\left(\chi^{2}(1)=4.45, p=.03\right)$. On the other hand, the simple main effect of the eyes when the recipient was an out-group member did not reach the significance level either in the analysis of variance $(F(1,136)=1.95, p=.17)$ or the log-linear analysis of fair allocation $\left(\chi^{2}(1)=0.55, p=.46\right)$. These results supported our hypothesis that the presence of stylized eyes would make people behave in a more altruistic way toward members of their own group, but not toward members of the other group.
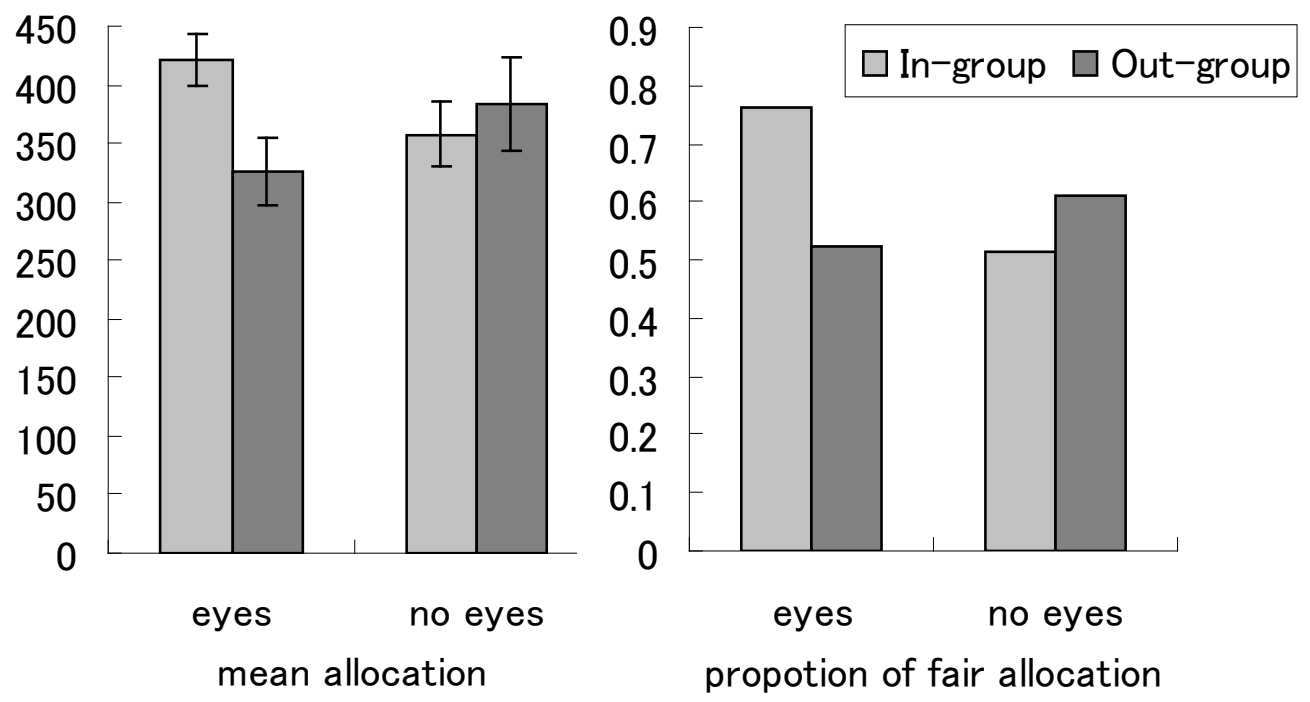
Figure 3 Mean amounts out of 900 yen the allocator gave to the in-group and the out-group recipients in the eyes condition and the no-eyes condition, and the proportions of allocators who gave fair offers in the two conditions. Error bars represent standard errors.

\section{GENERAL DISCUSSION}

The hypothesis concerning the effect of eyes, supported by the data from this study, is based on the fundamental assumption that sensitivity to monitoring by community members is a proximate mechanism to promote human adaptation to group life. We argued in the introduction that the proximate mechanism of human sensitivity to monitoring is based on the social mechanism to promote mutual cooperation within the group. We further argued that this social mechanism is based on the principle of indirect reciprocity. Being perceived to be altruistic toward community members is the critical condition for being accepted as a fully fledged member of the community with whom other members may interact with in an altruistic manner.

Indirect reciprocity, however, may not be the only reason why humans are sensitive to monitoring by community members. According to the strong reciprocity model of human cooperation (Fehr \& Gachter, 2002; Fehr \& Fischbacher, 2003; Gintis et al., 2003), humans have evolved an inclination toward punishing norm violators under group selection pressures. If this is the case, avoiding being identified as a norm violator, correctly or incorrectly, should be a major fitness concern for humans. Human sensitivity to monitoring thus may reflect the concern of becoming a potential target of punishment. Furthermore, since punishment of norm violators comes mostly from 
members of one’s own group rather than from non-members, as Shinada, Yamagishi, and Ohmura (2004) demonstrated, human sensitivity to monitoring is likely heightened when they are monitored by community members rather than by strangers.

This alternative explanation for sensitivity to cues of monitoring by community members, however, contradicts with experimental evidence that strong reciprocity including punishment of norm violators does not operate in minimal group settings (Koopmans \& Rebers, 2009). According to Koopmans and Rebers (2009) who argue that strong reciprocity has evolved through the process of cultural group selection, the psychology of strong reciprocity is not likely to operate in minimal groups that are so far removed from the actual group situations. If their argument is true, the sensitivity to cues of monitoring observed in the current study involving minimal groups would be hard to explain by fear of punishment. In order to find out if strong reciprocity and fear of punishment explain sensitivity to monitoring we observed in the current study, we first need to determine in future studies what aspects of actual groups is required for the psychology of strong reciprocity to operate.

This leads us to a discussion of the role that minimal groups play in studying human psychology of groups. Relevant on this issue is the finding that the manipulation of common versus private knowledge has no effect in actual groups in which face-to-face interactions are taking place (Makimura \& Yamagishi, 2003). It is thus clear that minimal groups are not the best place to study how people respond to the history of intra- and inter-group activities including conflicts over scarce resources. However, minimal groups are best suited for studying group-related psychological mechanisms that are activated by particular cues for situations in which the mechanism originally played an adaptive function. We believe that at least one aspect of the 
adaptive importance of groups for humans is that they provide a venue for indirect reciprocity to operate (Yamagishi \& Kiyonari, 2000). Thus, cues for the presence of reputation-based indirect reciprocity instigate psychological mechanisms adaptive to the system of indirect reciprocity even in minimal groups. We further believe that the operation of such psychological mechanisms is better studied in the context of minimal groups in which additional factors that could influence participants' group-related behaviors are absent.

It should be noted that the findings of our studies are consistent with results indicating that pro-social and norm-abiding behavior is promoted when people's attention is focused on their public selves (Froming, \& Carver, 1981; Froming, Nasby, \& McManus, 1998; Froming, Walker, \& Lopyan, 1982; Greenberg, 1983; Prentice-Dunn, \& Rogers, 1982). Particularly relevant is the finding that enhanced public self-awareness leads to behavior that meets the normal standard of the society and expectations from others (Froming, \& Carver, 1981; Froming, Walker, \& Lopyan, 1982). Our unique contribution to this literature stems from our finding that the cues of monitoring (which are likely to enhance public self-awareness) promote altruistic behavior toward in-group members, but not toward out-group members. This finding reveals the evolutionary foundations of public self-awareness as a means of motivating people to behave in an adaptive manner in a social environment of indirect reciprocity. From an evolutionary perspective, public self-awareness may be construed as a proximate mechanism that connects cues of monitoring to pro-social behavior toward community members.

In this study, participants' altruism toward in-group members was enhanced by the presence of eyes, which, we speculated, function as a cue for the presence of 
monitoring by community members. It is not certain, however, whether the eyes displayed on the screen were perceived by participants as eyes of community members; alternatively, it may be that the presence of eyes simply made them concerned with reputational implications of their behavior, and such concerns were mitigated when they found that the recipient was not a member of their own group. That is, eyes function as a cue for monitoring, and the presence of monitoring makes people behave in a more altruistic manner unless such behavior is irrelevant, that is, when such behavior is directed to outsiders of the community. Although the current study cannot answer this question, future studies that manipulate whether the eyes belong to community members or outsiders may shed light on this issue.

\section{References}

Barclay, P. (2004). Trustworthiness and competitive altruism can also solve the "tragedy of commons” Evolution and Human Behavior, 25, 209-220.

Barclay, P., \& Willer, R. (2007). Partner choice creates competitive altruism in humans. Proceedings of the Royal Society B - Biological Sciences, 274, 749-753.

Bateson, M., Nettle, D., \& Roberts, G. (2006). Cues of being watched enhance cooperation in a real-world setting. Biology Letters, 2, 412-414.

Berg, J., Dickhaut, J., \& McCabe, K. (1995). Trust, reciprocity, and social history. Games and Economic Behavior, 10, 122-42.

Bixenstine, V. E., Levitt, C. A., \& Wilson, K. V. (1966). Collaboration among six persons in a prisoner's dilemma game. Journal of Conflict Resolution, 10, 488-496.

Brechner, K. C. (1977). An experimental analysis of social trips. Journal of Experimental Social Psychology, 13, 552-564.

Burnham, T. C. (2003). Engineering altruism: a theoretical and experimental 
investigation of anonymity and gift giving. Journal of Economic Behavior \& Organization, 50, 133-144.

Burnham, T. C., \& Hare, B. (2007). Engineering human cooperation - Does involuntary neural activation increase public goods contributions? Human Nature, 18, 88-108.

Cosmides, L., \& Tooby, J. (1989). Evolutionary psychology and the generation of culture, part II. Case study: a computational theory of social exchange. Ethology and Sociobiology, 10, 51-97.

Dawes, R., McTavish, J., \& Shaklee, H. (1977). Behavior, communication and assumptions about other peoples' behavior in a commons dilemma situation. Journal of Personality and Social Psychology, 35, 1-11.

Fehr, E., \& Fischbacher, U. (2003). The nature of human altruism. Nature, 425, 785-791.

Fehr, E., \& Gachter, S. (2002). Altruistic punishment in humans. Nature, 415, 137-40.

Foddy, M., Platow, M. J., \& Yamagishi, T. (2009). Group-based trust in strangers: the role of stereotypes and expectations. Psychological Science, 20, 419-422.

Forsythe, R., Horowitz, J., Savin, N. E., \& Sefton, M. (1994). Fairness in simple bargaining experiments. Games and Economic Behavior, 6, 347-369.

Froming, W. J., \& Carver, C. S. (1981). Divergent influences of private and public self-consciousness in a compliance paradigm. Journal of Research in Personality, $15,159-171$.

Froming, W. J., Nasby, W., \& McManus, J. (1998). Prosocial self-schemas, self-awareness, and children's prosocial behavior. Journal of Personality and Social Psychology, 75, 766-777.

Froming, W. J., Walker, G. R., \& Lopyan, K. J. (1982). Public and private self-awareness: when personal attitudes conflict with societal expectations. Journal of Experimental Social Psychology, 18, 476-487.

Gintis, H., Bowles, S., Boyd, R., \& Fehr, E. (2003). Explaining altruistic behavior in humans. Evolution and Human Behavior, 24, 153-172.

Grieve, P. G., \& Hogg, M. A. (1999). Subjective uncertainty and intergroup discrimination in the minimal group situation. Personality and Social Psychology 
Bulletin, 25, 926-940.

Greenberg, J. (1983). Self-image versus impression management in adherence to distributive justice standards: the influence of self-awareness and self-consciousness. Journal of Personality and Social Psychology, 44, 5-19.

Haley, K. J., \& Fessler, D. M. T. (2005). Nobody's watching? Subtle cues affect generosity in an anonymous economic game. Evolution and Human Behavior, 26, 245-256.

Hamilton, W. D. (1964). The genetical evolution of social behavior. Journal of Theoretical Biology, 7, 1-52.

Henrich, J., McElreath, R., Barr, A., Ensminger, J., Barrett, C., Bolyanatz, A., Cardenas, J., Gurven, M., Gwako, E., Henrich, N., Lesorogol, C., Marlowe, F., Tracer, D., \& Ziker, J. (2006). Costly punishment across human societies. Science, 312, 1767-1770.

Hoffman, E., McCabe, K., \& Smith, V. (1996). Social distance and other-regarding behavior in dictator games. American Economic Review, 86, 653-60.

Horita, Y., \& Yamagishi, T. (2007). Adaptive foundations group-based reciprocity. Center for the Study of Cultural and Ecological Foundations of the Mind Working Paper Series, 70, Hokkaido University. (In Japanese).

Jin, N., \& Yamagishi, T. (1997). Group heuristics in social dilemma. Japanese Journal of Social Psychology, 12, 190-198. (In Japanese with an English abstract)

Kiyonari, T. (2002). Expectations of a generalized exchange system and ingroup favoritism: An experimental study of bounded reciprocity. Japanese Journal of Psychology, 73, 1-9. (In Japanese with an English abstract)

Kiyonari, T., Foddy, M., \& Yamagishi, T. (2007). Effects of direct and indirect exchange on trust of in-group members. Japanese Journal of Psychology, 77, 519-527. (In Japanese with an English abstract)

Koopmans, R., \& Rebers, S. (2009). Collective action in culturally similar and dissimilar groups: an experiment on parochialism, conditional cooperation, and their linkage. Evolution and Human Behavior, 30, 201-211.

Kurzban, R. (2001). The social psychophysics of cooperation: nonverbal communication in a public goods game. Journal of Nonverbal Behavior, 25, 
241-259.

Ledyard, J. O. (1995). Public goods. Pp. 111-194 in J. H. Kagel \& A. E. Roth (Ed.), Handbook of experimental economics. Princeton, NJ: Princeton University Press,

Leimar, O., \& Hammerstein, P. (2001). Evolution of cooperation through indirect reciprocity. Proceedings of the Royal Society of London Series B - Biological Science, 268, 745-753.

Makimura, Y., \& Yamagishi, T. (2003). Ongoing group interaction, ingroup favoritism, and reward allocation. Japanese Journal of Psychology, 73, 488-493. (In Japanese with an English abstract)

Messick, D. M., \& McClintock, C. G. (1968). Motivational bases of choice in experimental games. Journal of Experimental Social Psychology, 4, 1-25.

Milinski, M., Semmann, D., \& Krambeck, H. J. (2002). Donors to charity gain in both indirect reciprocity and political reputation. Proceedings of the Royal Society of London. Series B - Biological Sciences, 269, 881-883.

Nowak, M. A., \& Sigmund, K. (1998). Evolution of indirect reciprocity by image scoring. Nature, 393, 573-577.

Panchanathan, K., \& Boyd, R. (2004). Indirect reciprocity can stabilize cooperation without the second-order free rider problem. Nature, 432, 499-502.

Prentice-Dunn, S., \& Rogers, R. W. (1982). Effects of public and private self-awareness on deindividuation and aggression. Journal of Personality and Social Psychology, 43, 503-513.

Rigdon, M., Ishii, K., Watabe, M., \& Kitayama, S. (2009). Minimal social cues in the dictator game. Journal of Economic Psychology, 30, 358-367.

Shinada, M., Yamagishi, T., \& Ohmura, Y. (2004). False friends are worse than bitter enemy: 'Altruistic' punishment of in-group members. Evolution and Human Behavior, 25, 379-393.

Suzuki, N., Konno, Y., \& Yamagishi, T. (2007). In-group bias in trusting behavior: A choice of allocator experiment with minimal groups. Japanese Journal of Psychology, 78, 17-24. (In Japanese with an English abstract)

Trivers, R.L. (1971). The evolution of reciprocal altruism. Quarterly Review of Biology, 
46, 35-57.

Tajfel, H., Billig, M. G., Bundy, R. P., \& Flament, C. (1971). Social categorization and intergroup behaviour. European Journal of Social Psychology, 1, 149-178.

Takahashi, N., \& Mashima, R. (2006). The importance of subjectivity in perceptual errors on the emergence of indirect reciprocity. Journal of Theoretical Biology, 243, 418-436.

Wang, X. T. (1996). Domain-specific rationality in human choices: violation of utility axioms and social contexts. Cognition, 60, 31-63.

Yamagishi, T., Jin, N., \& Kiyonari, T. (1999). Bounded generalized reciprocity: Ingroup boasting and ingroup favoritism. Advances in Group Processes, 16, 161-197.

Yamagishi, T., \& Kiyonari, T. (2000). The group as the container of generalized reciprocity. Social Psychology Quarterly, 63, 116-132.

Yamagishi, T., Makimura, Y., Foddy, M., Matsuda, M., Kiyonari, T., \& Platow, M. J. (2005). Comparisons of Australians and Japanese on group-based cooperation. Asian Journal of Social Psychology, 8, 173-190.

Yamagishi, T., \& Mifune, N. (2008). Does shared group membership promote altruism? Fear, Greed, and Reputation. Rationality and Society, 20, 5-30.

Yamagishi, T., Mifune, N., Liu, J. H., \& Pauling, J. (2008). Exchange of group-based favours: Ingroup bias in the prisoner's dilemma game with minimal groups in Japan and New Zealand. Asian Journal of Social Psychology, 11, 196-207. 